\title{
Factors Affecting Depression among Married Women Living in Urban Squatter Settlements of Karachi, Pakistan
}

\author{
Shireen Shehzad Bhamani ${ }^{*}$, Salima Farooq1, Yasmin Parpio', Rozina Karmaliani1, \\ Nargis Asad ${ }^{2}$, Iqbal Azam³ ${ }^{3}$ Omrana Pasha ${ }^{3}$ \\ ${ }^{1}$ School of Nursing and Midwifery, Aga Khan University, Karachi, Pakistan \\ ${ }^{2}$ Department of Psychiatry, Aga Khan University, Karachi, Pakistan \\ ${ }^{3}$ Department of Community Health Sciences, Aga Khan University, Karachi, Pakistan \\ Email: "shireen.shehzad@aku.edu, "bhamanishireen@gmail.com, salima.farooq@aku.edu, \\ yasmin.parpio@aku.edu, rozina.karmaliani@aku.edu,nargis.asad@aku.edu, iqbal.azam@aku.edu, \\ omrana.pasha@aku.edu
}

Received 11 January 2016; accepted 20 February 2016; published 23 February 2016

Copyright (C) 2016 by authors and Scientific Research Publishing Inc.

This work is licensed under the Creative Commons Attribution-NonCommercial International License (CC BY-NC).

http://creativecommons.org/licenses/by-nc/4.0/

(c) () (9) Open Access

\section{Abstract}

Background: Depression is one of the growing public health concerns among women worldwide. This is one of the most under-recognized and under-treated mental illnesses worldwide. Women of developing countries are inexplicably affecting with depression. Purpose: The purpose of study is to assess the prevalence and associative factors of depression among women of aged 20 to 40 years living in urban squatter settlements of Karachi, Pakistan. The identification of all the potential determinants will potentially help in formulating preventive strategies in order to decline the prevalence of depression among women and improve the wellbeing of women. Methods: An analytical cross-sectional survey was employed among women living in Reta Plot and Kala Board communities of Karachi, Pakistan. Beck Depression Inventory II (BDI-II) was used to measure depression. Systematic sampling was used to recruit 636 married women. Cox proportional hazard was run to compute prevalence ratios and their $95 \%$ confidence interval. Results: Our study estimated $33.3 \%$ of depression among study participants. The current study showed that age, possession of own vehicle, years of schooling and recent deaths in family were significantly associated with depression. Conclusion: This research was a bold step to address the issue of increasing rate of depression among Pakistani population. Our study results can convince policy makers to extend mental health support to women by improving accessibility of services. Recommendation: Our study recommends that the women of our society should be encouraged for attaining education. This study also recommends that at primary health care setting, every health professional should

${ }^{*}$ Corresponding author.

How to cite this paper: Bhamani, S.S., Farooq, S., Parpio, Y., Karmaliani, R., Asad, N., Azam, I. and Pasha, O. (2016) Factors Affecting Depression among Married Women Living in Urban Squatter Settlements of Karachi, Pakistan. Open Journal of Epidemiology, 6, 80-87. http://dx.doi.org/10.4236/ojepi.2016.61008 
be trained to screen the depression. Moreover, the results of our study can also encourage policy makers to expand mental health support services for women.

\author{
Keywords
}

Depression, Prevalence Ratio, Married Women

\title{
1. Introduction
}

Depression is highly prevalent in general population [1]. One in four people struggles with mental illness such as depression, anxiety, substance misuse disorder during their lives [2]. Depression has greater morbidity and mortality impact in comparison to physical illness [3] as it impacts on thinking, feeling, emotion, behavior, relationship, functioning and also diminish social role, education, and productivity [4]. Depression is the fourth leading cause of disease burden [5]; however, it will be the second leading cause of disability and death by 2020 after heart disease [6]. Depression is one of the most under-recognized and under-treated mental illnesses worldwide [7]. Only marginal people received treatment worldwide for mental disorder [8].

Depression is one of the rising public health concerns among women [8] [9] as they are disproportionately affecting with depression specifically in developing countries [10]. Depression is twice as common in women as in men. Prevalence of depression among women in Pakistan is $29 \%$ to $66 \%$ [11] and for men it was $10 \%$ to $33 \%$ [12]. Depression is the leading cause of disease-related disability among women [13].

According to the available literature, determinants of depression among women in Pakistan include: marital status, lack of social support, marital dissatisfaction, educational levels and family type [14]. Woman's silence about her emotional, social and physical needs is also associated with women's depression [11]. Previous research revealed that gender discrimination is strongly linked with psychological morbidity among women in Pakistan [10]. According to Mirza, 2004, relationship and adjustment difficulties with husband and in-laws, number of children and financial difficulties were found to be associated with depression [15]. Moreover, death of a loved one [16] and increasing age of married women are also associated with depression [17] whereas, social, and family support are "considered as buffering agents or protective factors against depression” [18] [19].

The identification of all the potential determinants will potentially help in formulating preventive strategies in order to decline the prevalence of depression among women. Given the limited health resources in country, mental health is mostly neglected and hence, the toll of depression is expanding day by day. Therefore, it is imperative to give attention to this ignored area. This particular study will estimate the prevalence and identify the factors associated with depression among married women aged 20 to 40 years in Karachi, Pakistan.

\section{Methods}

This research is a sub-analysis of a parent study. The methodology has been explicitly stated in parent study elsewhere [20]. An analytical cross-sectional design was employed in the current study to achieve the study objectives. The study population was comprised of all married women of aged 20 - 40 years living in Urban Squatter settlements of Karachi Pakistan. Because married women are more prone to be depressed that men because they have most responsibilities and they are the one who generally faces ups and downs of life. Therefore, we have chosen married women.

Systematic random sampling was utilized to recruit 636 married women. Face to face interviews were performed to collect data. The outcome variable was assessed through Beck Depression Inventory-II (BDI-II). This tool has 21 items and each item consists of 4 options and the total scores ranged from 0 to 63 . The binary cut-off of being depressed is 17 score and above. The demographic profile of the participants was evaluated by a selfdeveloped form that consist of demographic and psychosocial factors like: age, education, number of family members, type of marriage and family, duration of marriage, number of children, number of people living in the house, working status and possession of own vehicle and house. In addition, support groups that include friends, involvement in social activities and recent life events were also determined.

Statistical Package for the Social Sciences (SPSS), version 19.0 was used for data analysis. Descriptive statistics like frequencies \& proportions were computed for categorical variables; whereas, means and standard devi- 
ations were run for continuous variables. For inferential statistics, Cox regression model was run to estimate Prevalence ratio (PRs) with their 95\% confidence intervals (CIs).

Approval of study protocol was sought from the institutional ethical review committee before starting the data collection process. Verbal and written consent were sought from participants.

\section{Results}

Our study results found the prevalence of depression as 33.3\% among married women of aged 20 to 40 years living in urban squatter settlements. Table 1 presents the socio-demographic status of the study participants. The study participants of depressed group were significantly $(p<0.05)$ different than their counterpart with regard to their mean age, years of schooling, duration of marriage, age of youngest child and number of children; whereas, monthly income and number of people living in household were insignificant $(p>0.05)$.

Table 2 shows the association of different socio-demographic variables with the depression status. Education status both formal or informal schooling and possession of own house and vehicle were significantly associated with depression $(p<0.05)$. Whereas, type of marriage, marriage with in family, working status, having friends and involving in social activities have found independent of depression status $(p>0.05)$. In addition, recent death in family shows significant association with the depression status.

The univariate analysis was evaluated with all the demographic and psychosocial variables. The cut-off of ( $p<$ 0.25 ) was set to find the associated factors at univariate level. Therefore, number of variables including age, formal schooling and possession of own house were found to be associated with depression at a $p$-value of $<0.25$ and therefore also included in the multivariable analysis (refer Table 3).

Table 4 presents the final cox regression model which includes: age (in years), possession of own vehicle, years of schooling and recent deaths in family.

It was observed that after adjusting for the other covariates, with every 1 year increase in age, the prevalence of having depression was increased by $1.8 \%$. (CI: 0.994 to 1.042). Though the age was insignificant at multivariable analysis but was kept in model based on its biological importance. Also, with every 1 year increase in school education, the prevalence of having depression was decreased by $4.7 \%$ (CI: 0.923 to 0.984 ). The prevalence of depression was 1.339 times more among those having no vehicle than those who have their own vehicle (CI: 1.015 to 1.766). The prevalence of depression was 1.334 times more among those who faced recent deaths in family as compared to those who have no deaths. There was no interaction found in the model.

\section{Discussion}

The study has reported 33\% Depression among women aged 20 to 40 yrs in Karachi, Pakistan. The findings of the current research is consistent with previous studies who have reported the prevalence of Depression ranging from $30 \%$ to $66 \%$ among married women in Pakistan [21] [22]. The plausible reason for varying prevalence could be the use of different diagnostic tools in various studies. In addition, there were differences in the distribution of marital status, geographical background urban versus rural.

Table 1. Socio demographic status of married women in Urban Squatter Settlement in Karachi, Pakistan $(n=636)$.

\begin{tabular}{|c|c|c|c|c|}
\hline Variables & $\begin{array}{c}\text { Depressed }(n=212) \\
\text { mean }(+\mathrm{SD})\end{array}$ & $\begin{array}{c}\text { Not depressed }(n=424) \\
\text { mean }(+S D)\end{array}$ & $\mathbf{t}$ & $p$-value \\
\hline Age & $31.56(5.4)$ & $30.46(5.7)$ & -2.309 & $0.021^{*}$ \\
\hline Yr of schooling & $6.96(4.2)$ & 8.52 (3.9) & 4.579 & $<0.000^{*}$ \\
\hline Number of children & $3.14(2.0)$ & $2.68(1.8)$ & -2.862 & $0.004^{*}$ \\
\hline Age of youngest child & $6.39(4.8)$ & $5.4(4.0)$ & -2.418 & $0.016^{*}$ \\
\hline Monthly income & $11367.92(5522.2)$ & $12191.04(9015.3)$ & 1.22 & 0.223 \\
\hline Number of people in household & $6.51(3.46)$ & $6.96(3.4)$ & 1.515 & 0.123 \\
\hline Duration of marriage & $13.02(7.2)$ & $10.86(6.9)$ & -3.643 & $<0.001$ \\
\hline
\end{tabular}

${ }^{*} p<0.05$ significant. 
Table 2. Demographic and psychosocial factors of married women in Urban Squater Settlement in Karachi, Pakistan $(\mathrm{n}=$ 636).

\begin{tabular}{|c|c|c|c|c|}
\hline Variables & Depressed $(n=212)$ n (\%) & Not depressed $(n=424)$ n (\%) & $X^{2}$ & $p$-value \\
\hline \multicolumn{5}{|c|}{ Formal schooling } \\
\hline Yes & $172(81.1)$ & $379(89.4)$ & 8.317 & $0.004^{*}$ \\
\hline No & $40(19.9)$ & $45(10.6)$ & & \\
\hline \multicolumn{5}{|c|}{ Informal schooling } \\
\hline yes & $153(72.2)$ & 354 (83.5) & 11.202 & $0.001^{*}$ \\
\hline No & $59(27.8)$ & $70(16.5)$ & & \\
\hline \multicolumn{5}{|c|}{ Type of marriage } \\
\hline Arrange & $184(86.8)$ & 380 (89.6) & 1.128 & 0.288 \\
\hline Self-choice & $28(13.2)$ & $44(10.4)$ & & \\
\hline \multicolumn{5}{|c|}{ Married with the relatives } \\
\hline Yes & $101(47.6)$ & $234(55)$ & 3.229 & 0.072 \\
\hline No & $111(52.4)$ & $190(45)$ & & \\
\hline \multicolumn{5}{|l|}{ Type of family } \\
\hline Nuclear & $75(35.4)$ & 199 (46.9) & 7.698 & 0.006* \\
\hline Extended & $137(64.6)$ & $225(53.1)$ & & \\
\hline \multicolumn{5}{|c|}{ Working status } \\
\hline Yes & $28(13.2)$ & $68(16)$ & 0.883 & 0.347 \\
\hline No & $184(86.8)$ & $356(84)$ & & \\
\hline \multicolumn{5}{|l|}{ Own house } \\
\hline Yes & $127(59.9)$ & $293(69.1)$ & 5.332 & 0.021 \\
\hline No & $85(40.1)$ & $131(29.9)$ & & \\
\hline \multicolumn{5}{|l|}{ Own vehicle } \\
\hline Yes & $89(42)$ & 237 (55.9) & 10.953 & $\mathbf{0 . 0 0 1}^{*}$ \\
\hline No & $123(58)$ & $187(44.1)$ & & \\
\hline \multicolumn{5}{|c|}{ Friends/supporters } \\
\hline Yes & $73(34.4)$ & $150(35.4)$ & 0.055 & 0.814 \\
\hline No & $139(65.6)$ & 274 (64.6) & & \\
\hline \multicolumn{5}{|c|}{ Involve in social activity } \\
\hline Yes & $12(5.6)$ & $21(4.9)$ & 0.144 & 0.705 \\
\hline No & $200(94.4)$ & $403(95.1)$ & & \\
\hline \multicolumn{5}{|c|}{ Recent deaths in family } \\
\hline Yes & 95 (45) & $144(34)$ & 7.092 & 0.008 \\
\hline No & $117(55)$ & $280(66)$ & & \\
\hline
\end{tabular}

${ }^{*} p<0.05$ significant. 
Table 3. Univariate analysis for factors associated with depression.

\begin{tabular}{|c|c|c|c|c|}
\hline \multirow{3}{*}{ Variables } & \multicolumn{2}{|c|}{ Depression } & \multirow{3}{*}{ Crude prevalence ratio } & \multirow{3}{*}{$p$-value } \\
\hline & Yes $(n=212)$ & No $(n=424)$ & & \\
\hline & n (\%) & n (\%) & & \\
\hline Age $^{\wedge}$ & $31.56(5.4)$ & $30.46(5.7)$ & 1.023 & 0.06 \\
\hline Yr of schooling^ & $6.96(4.2)$ & $8.52(3.9)$ & 0.944 & $<0.001$ \\
\hline No. of children ^ & $3.14(2.0)$ & $2.68(1.8)$ & 1.08 & 0.02 \\
\hline 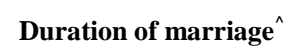 & $13.02(7.2)$ & $10.86(6.9)$ & 1.028 & 0.003 \\
\hline \multicolumn{5}{|l|}{ Formal schooling } \\
\hline Yes & $172(81.1)$ & $379(89.4)$ & 0.663 & 0.19 \\
\hline No & 40 (19.9) & $45(10.6)$ & 1 & \\
\hline \multicolumn{5}{|l|}{ Informal schooling } \\
\hline yes & $153(72.2)$ & 354 (83.5) & 0.66 & 0.007 \\
\hline No & $59(27.8)$ & 70 (16.5) & 1 & \\
\hline \multicolumn{5}{|l|}{ Possession of own house } \\
\hline Yes & 127 (59.9) & $293(69.1)$ & 1 & 0.06 \\
\hline No & $85(40.1)$ & $131(29.9)$ & 1.301 & \\
\hline \multicolumn{5}{|l|}{ Possession of own vehicle } \\
\hline Yes & $89(42)$ & 237 (55.9) & 1 & 0.007 \\
\hline No & $123(58)$ & $187(44.1)$ & 1.453 & \\
\hline \multicolumn{5}{|l|}{ Recent deaths in family } \\
\hline Yes & $95(45)$ & 144 (34) & 1.348 & 0.03 \\
\hline No & $117(55)$ & $280(66)$ & 1 & \\
\hline
\end{tabular}

${ }^{\wedge}$ Mean (SD) for continuous variables.

Table 4. Multivariable analysis for factors associated with depression.

\begin{tabular}{|c|c|c|c|c|}
\hline Variables & $\begin{array}{l}\text { Prevalence of depression } \\
\quad(n=212) n(\%)\end{array}$ & $\begin{array}{l}\text { Prevalence of no depression } \\
(n=424) n(\%)\end{array}$ & $\begin{array}{c}\text { Crude } \\
\text { prevalence ratio }\end{array}$ & $\begin{array}{l}\text { Adjusted prevalence } \\
\text { ratio }(95 \% \mathrm{CI})\end{array}$ \\
\hline Age in years $\wedge$ & $31.56(5.4)$ & 30.46 (5.7) & 1.023 & $1.018(0.994$ to 1.042$)$ \\
\hline Year of schooling^ $\wedge$ & $6.96(4.2)$ & 8.52 (3.9) & 0.944 & $0.953(0.923$ to 0.984$)$ \\
\hline \multicolumn{5}{|l|}{ Possession of own vehicle } \\
\hline Yes & $89(42)$ & 237 (55.9) & 1 & 1 \\
\hline No & $123(58)$ & $187(44.1)$ & 1.453 & $1.339(1.015$ to 1.766$)$ \\
\hline \multicolumn{5}{|l|}{ Recent deaths in family } \\
\hline Yes & $95(45)$ & $144(34)$ & 1.348 & 1.334 (1.018 to 1.749$)$ \\
\hline No & 117 (55) & $280(66)$ & 1 & \\
\hline
\end{tabular}

${ }^{\wedge}$ Mean (SD) for continuous variables.

The current study showed that age, own vehicle, years of schooling and recent deaths in family were significantly associated with Depression in this population. Age was not found to be significant but it was added in 
multivariable model due to its biological significance. Our study finding is consistent with a study done in past [22]. In contrast, other studies showed that increasing age of women is correlated with depression [17] [23]. Hence, further researchers are required to clarify this discrepancy.

It is well established that women who belong to low socio-economic group are at increased risk for Depression [17] [24] [25]. This fact is endorsed in our study as participants who were not having own vehicle were $45 \%$ times more prone for depression. In our study, having own vehicle was taken as a proxy indicator to assess socio economic status of participant and was found to be a protective study. The plausible explanation of mental wellbeing with own vehicle could be that it increases opportunities for women to get engage in leisure activities outside home with spouse, friends and families which eventually promote positive coping skills. On the contrary, a study by Zainab and colleague found no difference in prevalence of depression among low and high SES groups [22].

Our study identified that year of schooling is inversely linked with Depression. The results are aligned with the findings extracted from past studies [12] [23] [24] [26]. Education is considered as a buffering against Depression as with increased years of education, women are more equipped with autonomy, decision making capability, confidence and social skills.

A major life circumstances such as death is a permanent loss and major life stressor that can dispose women to poor mental health [27] [28]. Our study showed that a significant rise in prevalence ratio of depression among women with history of death of family member was also positively correlated with depression in our study. In the same line, previous studies have also shown a positive association between depression and death of a family member in recent years [4].

The results can be generalized to urban married women population as this study captured a large community based sample. Moreover, we used a standardized and rigorous procedure of tool translation and trained CHWs three times during data collection process to be more precise and accurate in obtaining information from the participants and reinforcing the protocol guidelines. Lastly, in our study, referral was given to all participants who were found severely depressed and were provided counseling by PI.

Our study has certain limitations that need to be considered while drawing conclusion. There are several important determinants like, family history of Depression, current illness and death of parents in recent year, coping styles and religious practices needs to address in future study. Some of the questions were of a personal nature so there might be some reporting bias which may underestimate or overestimated the prevalence of Depression in our study. In addition, this was a cross-sectional study, so we could not establish a temporal relationship between predictors and outcome.

\section{Conclusion}

Our study has reported a 33\% prevalence of depression among women aged 20 to 40 years in Karachi, Pakistan and revealed that increased age, years of schooling, possession of own vehicle, and death of family members in recent years were major determinants of Depression. Further researches are required to explore the factors which were not unveiled in the current study. This research is not only an attempt to fill the existing gaps in literature, but also a step to address the issue of increasing rate of depression among Pakistani population. Our study recommends that the women of our society should be encouraged for attaining education. This study also recommends that at primary health care setting, every health professional should be trained to screen the depression. Moreover, the results of our study can also encourage policy makers to expand mental health support services for women.

\section{Acknowledgements}

SSB, RK, IA, NA and OP have made substantial contributed in the study's conception, operationalization, analysis and drafting the manuscript. SF and YP have given the extensive input in setting the background and discussion of current manuscript. Special gratitude to all those married women who participated in this survey. Moreover, thanks to stakeholders of selected urban squatter settlements for allowing us to collect data from their territory.

The author and the co-authors of this study declare that they have no competing interest.

\section{References}

[1] Kessler, R.C., Aguilar-Gaxiola, S., Alonso, J., Chatterji, S., Lee, S., Ormel, J., Ustün, T.B. and Wang, P.S. (2009) The Global Burden of Mental Disorders: An Update from the WHO World Mental Health (WMH) Surveys. Epidemiologia 
e Psichiatria Sociale, 18, 23-33. http://dx.doi.org/10.1017/S1121189X00001421

[2] WHO (2003) Investing in Mental Health. In: Investing in Mental Health Series Investing in Mental Health.

[3] Lahariya, C., Singhal, S., Gupta, S. and Mishra, A. (2010) Pathway of Care among Psychiatric Patients Attending a Mental Health Institution in Central India. Indian Journal of Psychiatry, 52, 333. http://dx.doi.org/10.4103/0019-5545.74308

[4] Altaf, A., Khan, M., Shah, S.R., Fatima, K., Tunio, S.A., Hussain, M., Khan, M.A., Shaikh, M.A. and Arshad, M.H. (2015) Sociodemographic Pattern of Depression in Urban Settlement of Karachi, Pakistan. Journal of Clinical and Diagnostic Research, 9, VC09. http://dx.doi.org/10.7860/jcdr/2015/12611.6093

[5] Moussavi, S., Chatterji, S., Verdes, E., Tandon, A., Patel, V. and Ustun, B. (2007) Depression, Chronic Diseases, and Decrements in Health: Results from the World Health Surveys. The Lancet, 370, 851-858. http://dx.doi.org/10.1016/S0140-6736(07)61415-9

[6] WHO (2004) The Global Burden of Disease. In: The Global Burden of Disease, Series: The Global burden of Disease.

[7] Bhugra, D. and Mastrogianni, A. (2004) Globalisation and Mental Disorders Overview with Relation to Depression. The British Journal of Psychiatry, 184, 10-20. http://dx.doi.org/10.1192/bjp.184.1.10

[8] Diego-Adellino, J.D., Portella, M.J., Puigdemont, D., Perez-Egea, R., Alvarez, E. and Perez, V. (2010) A Short Duration of Untreated Illness (DUI) Improves Response Outcomes in First-Depressive Episodes. Journal of Affective Disorders, 120, 221-225. http://dx.doi.org/10.1016/j.jad.2009.03.012

[9] Vyas, A. and Sambamoorthi, U. (2011) Multimorbidity and Depression Treatment. General Hospital Psychiatry, 33, 238-245. http://dx.doi.org/10.1016/j.genhosppsych.2011.02.009

[10] Qadir, F., Khan, M.M., Medhin, G. and Prince, M. (2011) Male Gender Preference, Female Gender Disadvantage as Risk Factors for Psychological Morbidity in Pakistani Women of Childbearing Age-A Life Course Perspective. BMC Public Health, 11, 745. http://dx.doi.org/10.1186/1471-2458-11-745

[11] Amir, F.A. and Zuberi, R.W. (2012) Association of Sociodemographic Factors with Depression in Women of Reproductive Age. Asia-Pacific Journal of Public Health, 24, 161-172. http://dx.doi.org/10.1177/1010539510364668

[12] Qadir, F., Khalid, A., Haqqani, S. and Medhin, G. (2013) The Association of Marital Relationship and Perceived Social Support with Mental Health of Women in Pakistan. BMC Public Health, 13, 1150. http://dx.doi.org/10.1186/1471-2458-13-1150

[13] Kessler, R.C., Berglund, P., Demler, O., Jin, R., Merikangas, K.R. and Walters, E.E. (2005) Lifetime Prevalence and Age-of-Onset Distributions of DSM-IV Disorders in the National Comorbidity Survey Replication. Archives of General Psychiatry, 62, 593-602. http://dx.doi.org/10.1001/archpsyc.62.6.593

[14] Zainal, N.Z. (2008) Depressive Symptoms in Middle-Aged Women in Peninsular Malaysia. Asia-Pacific Journal of Public Health, 20, 360-369. http://dx.doi.org/10.1177/1010539508322538

[15] Mirza, I. and Jenkins, R. (2004) Risk Factors, Prevalence, and Treatment of Anxiety and Depressive Disorders in Pakistan: Systematic Review. BMJ, 328, 794. http://dx.doi.org/10.1136/bmj.328.7443.794

[16] Melhem, N.M., Porta, G., Shamseddeen, W., Payne, M.W. and Brent, D.A. (2011) Grief in Children and Adolescents Bereaved by Sudden Parental Death. Archives of General Psychiatry, 68, 911-919. http://dx.doi.org/10.1001/archgenpsychiatry.2011.101

[17] Nisar, N., Billoo, N. and Gadit, A.A. (2004) Prevalence of Depression and the Associated Risks Factors among Adult Women in a Fishing Community. Journal of the Pakistan Medical Association, 54, 519-525.

[18] Luni, F.K., Ansari, B., Jawad, A., Dawson, A. and Baig, S.M. (2009) Prevalence of Depression and Anxiety in a Village in Sindh. Journal of Ayub Medical College Abbottabad, 21, 68-72.

[19] Mair, C.F., Roux, A.V.D. and Galea, S. (2008) Are Neighborhood Characteristics Associated with Depressive Symptoms? A Critical Review. Journal of Epidemiology and Community Health, 6, 940-946.

[20] Bhamani, S.S., Pasha, O., Karmaliani, R., Asad, N. and Azam, I. (2015) Validation of the Urdu Version of Wagnild and Young's Long and Short Resilience Scales Among 20-to 40-Year-Old Married Women Living in Urban Squatter Settlements of Karachi, Pakistan. Journal of Nursing Measurement, 23, 425-435. http://dx.doi.org/10.1891/1061-3749.23.3.425

[21] Zahidie, A. and Jamali, T. (2013) An Overview of the Predictors of Depression among Adult Pakistani Women. Journal of the College of Physicians and Surgeons Pakistan, 23, 574-580.

[22] Zainab, S., Fatmi, Z. and Kazi, A. (2012) Risk Factors for Depression among Married Women Belonging to Higher and Lower Socioeconomic Status in Karachi, Pakistan. Journal of the Pakistan Medical Association, 62, 249-253.

[23] Husain, N., Gater, R., Tomenson, B. and Creed, F. (2004) Social Factors Associated with Chronic Depression among a Population-Based Sample of Women in Rural Pakistan. Social Psychiatry and Psychiatric Epidemiology, 39, 618-624. http://dx.doi.org/10.1007/s00127-004-0781-1 
[24] Ali, B.S., Rahbar, M.H., Tareen, A.L., Gui, A., Samad, L. and Naeem, S. (2002) Prevalence of and Factors Associated with Anxiety and Depression among Women in a Lower Middle Class Semi-Urban Community of Karachi, Pakistan. Journal of the Pakistan Medical Association, 52, 513-517.

[25] Mumford, D.B., Minhas, F.A., Akhtar, I., Akhter, S. and Mubbashar, M.H. (2000) Stress and Psychiatric Disorder in Urban Rawalpindi. The British Journal of Psychiatry, 177, 557-562. http://dx.doi.org/10.1192/bjp.177.6.557

[26] Douki, S., Zineb, S.B., Nacef, F. and Halbreich, U. (2007) Women’s Mental Health in the Muslim World: Cultural, Religious, and Social Issues. Journal of Affective Disorders, 102, 177-189. http://dx.doi.org/10.1016/j.jad.2006.09.027

[27] Rab, F., Mamdou, R. and Nasir, S. (2008) Rates of Depression and Anxiety among Female Medical Students in Pakistan. Eastern Mediterranean Health Journal, 14, 126-133.

[28] Rashid, S.A. (2011) Comparison of Mental Health of Females Belonging to Single and both Biological Parents. International Journal of Humanities and Social Science, 1, 236-243. 